Effects of matrix composition and configuration on forest bird movements in a fragmented Afromontane biodiversity hot spot

\begin{abstract}
Aben, J.
2012-12

Aben , J, Adriaensen , F , Thijs , K W , Pellikka , P , Siljander , M , Lens , L \& Matthysen , E 2012 , ' Effects of matrix composition and configuration on forest bird movements in a fragmented Afromontane biodiversity hot spot ' , Animal Conservation , vol. 15 , no. 6 , pp. 658-668 . https://doi.org/10.1111/j.1469-1795.2012.00562.x
\end{abstract}

http://hdl.handle.net/10138/44812

https://doi.org/10.1111/j.1469-1795.2012.00562.x

publishedVersion

Downloaded from Helda, University of Helsinki institutional repository.

This is an electronic reprint of the original article.

This reprint may differ from the original in pagination and typographic detail.

Please cite the original version. 


\title{
Effects of matrix composition and configuration on forest bird movements in a fragmented Afromontane biodiversity hotspot
}

\author{
J. Aben ${ }^{1}$, F. Adriaensen ${ }^{1}$, K. W. Thijs ${ }^{2}$, P. Pellikka ${ }^{3}$, M. Siljander ${ }^{3}$, L. Lens ${ }^{4,5}$ \& E. Matthysen ${ }^{1}$ \\ 1 Evolutionary Ecology Group, Department of Biology, University of Antwerp, Antwerp, Belgium \\ 2 Division Forest, Nature and Landscape, KU Leuven, Leuven, Belgium \\ 3 Department of Geosciences and Geography, University of Helsinki, Helsinki, Finland \\ 4 Terrestrial Ecology Unit, Department of Biology, Ghent University, Ghent, Belgium \\ 5 Ornithology Section, Zoology Department, National Museums of Kenya, Nairobi, Kenya
}

\section{Keywords}

animal movement; forest fragmentation; habitat connectivity; habitat selection; Taita Hills; tropical forest birds.

\section{Correspondence}

Job Aben, Evolutionary Ecology Group, Department of Biology, University of Antwerp, Groenenborgerlaan 171, 2020

Antwerp, Belgium. Tel: +32 3265 3489;

Fax: +32 32653474

Email: job.aben@gmail.com

Editor: Res Altwegg

Associate Editor: Carman Bessa-Gomes

Received 25 January 2012; accepted 11 May 2012

doi:10.1111/j.1469-1795.2012.00562.x

\begin{abstract}
Persistence of forest-dependent species in fragmented landscapes strongly relies on sufficient dispersal between patches, making it important to understand how animal movements are affected by the intervening matrix. Movements can be influenced through selection or avoidance of land cover based on their perceived suitability for foraging or providing cover. The composition and configuration of the matrix will, therefore, most likely be an important factor to consider when estimating connectivity between patches. To address this, we performed translocation experiments to understand how forest birds used different land cover types in a fine-grained matrix of a fragmented Afromontane biodiversity hotspot (Taita Hills, Kenya). Our results revealed that use of land cover types for both the forest specialist Cabanis's greenbul Phyllastrephus cabanisi and for the forest generalist white-starred robin Pogonocichla stellata was disproportional to their availability. However, this effect was influenced by matrix configuration; in patchy matrices, land cover selection was more pronounced compared with more uniform matrices, especially for the forest specialist. At the scale of movement steps, risk avoidance seemed to be a strong factor in the route decisions for both species. Observed steps contained on average lower proportions of open land cover and did less frequently intersect built-up areas than expected. P. stellata did not differentiate between the alternative land cover types, whereas $P$. cabanisi preferred steps that contained more indigenous forest. The observed negative relationship between degree of forest dependency and matrix permeability implies that for members of the Taita bird community, which are even more dependent on intact forest habitat (i.e. the critically endangered Taita thrush Turdus helleri), current permeability of the matrix may be even lower. Matrix restoration to improve connectivity may, therefore, be a crucial instrument for the long-term survival of forest-dependent species in these fragmented Afromontane landscapes.
\end{abstract}

\section{Introduction}

Forest conversion has a detrimental effect on biodiversity in tropical landscapes (Gibson et al., 2011). While species richness of forest-dependent taxa ultimately depends on the total area and quality of remaining habitat (Gibson et al., 2011), long-term survival of populations will additionally depend on the connectivity of the landscape matrix when habitat becomes more fragmented (Lens et al., 2002). However, progressive intensification of land use in the tropics makes matrices increasingly impermeable for forest-dependent species (Estrada, Coates-Estrada \& Meritt, 1997; Edwards et al., 2010; Phalan et al., 2011) with associated negative consequences for functional connectivity [frequency and numbers of movement of individuals among fragments (Taylor et al., 1993)] (Stouffer \& Bierregaard, 1995; Levey et al., 2005). Nevertheless, even for highly mobile and well-studied taxa such as birds, the effects of landscape matrices on movement are still poorly understood. To our knowledge, only two studies have described movement behaviour of birds in novel matrix environments in detail by using continuous radio-tracking 
(Gillies \& St. Clair, 2008, 2010; Hadley \& Betts, 2009; Gillies, Beyer \& St. Clair, 2011). However, both studies were performed in matrices with a relatively simple structure and strong contrasts between land cover types, which is typical for intensively managed tropical landscapes. In this paper, we analyzed movement data of tropical forest birds collected in a much more fine-grained and less contrasting matrix.

The Eastern Arc Mountains (EAM), stretching from southern Kenya to southern Tanzania, are part of one of the most important global biodiversity hotspots (Myers et al., 2000) and contain relatively dense rural populations that are reliant on farming for their livelihood (Burgess et al., $2007 a$ ), which has resulted in a forest loss of $80 \%$ (Hall et al., 2009). The highly fragmented indigenous forest remains embedded in landscapes dominated by low-yielding mosaic agriculture leading to fine-grained, heterogeneous matrices. The fact that many of these fragments only contain a subset of the regional avifauna (Newmark, 1991; Lens et al., 2002) suggests that even these fine-grained matrices strongly impede dispersal of forest bird species. Recent genetic work confirms that several forest understory birds have limited gene flow leading to genetic differentiation between fragmented populations (Callens et al., 2011).

We conducted translocation experiments and quantified relative land cover selection for two bird species typical for the cloud forests of the EAM, Cabanis's greenbul Phyllastrephus cabanisi placidus and white-starred robin Pogonocichla stellata helleri, which differ in their dependence on indigenous forest (Lens et al., 1999) and overall mobility (Lens et al., 2002; Callens et al., 2011). As in other studies cited above, we assume that movements observed during translocations are sufficiently similar to movement behaviour during spontaneous dispersal events in order to provide meaningful measures of landscape connectivity (Belisle, 2005; Gillies \& St. Clair, 2008).

We analyzed land cover use during movements both with respect to point locations (i.e. actual land cover use by birds in between flights) and movement steps (i.e. land cover covered during flights). Both give complementary information on the importance of land cover for dispersal. While point locations can be regarded to primarily reflect perceived land cover suitability for foraging opportunities and/or providing shelter, movement steps necessarily have to include suboptimal land cover types in order to achieve spatial displacement, and therefore reflect the resistance of different land cover types to movement (Gillies \& St. Clair, 2010; Gillies et al., 2011). In addition, we directly tested for responses to ecotones by comparing movement angles of birds approaching different types of boundaries between land cover types. Identifying effects of these matrix attributes on movement for two forest bird species with contrasting forest dependency will potentially provide us with more power to extrapolate our findings into connectivity estimates for members of the Taita forest bird community which are of international conservation concern (i.e. the endemic Taita thrush Turdus helleri and Taita apalis Apalis fuscigularis).

\section{Materials and methods}

\section{Study area}

Translocation experiments were conducted in the Taita Hills $\left(03^{\circ} 20^{\prime} \mathrm{S}, 38^{\circ} 15^{\prime} \mathrm{E}\right)$ in south-east Kenya (Fig. 1). This mountain block represents the northernmost part of the EAM and is strongly isolated from other highland areas by the dry coastal Tsavo plains. Because climatic conditions are favourable for agriculture, extensive cloud forest clearing occurred, resulting in a reduction of the original forest cover by 70-98\% (Beentje, 1988; Myers et al., 2000). At present, three larger fragments [Chawia (86 ha), Ngangao (120 ha) and Mbololo (185 ha)], nine smaller ones ( $<8 \mathrm{ha})$ and several tiny patches of indigenous forest remain embedded in a fine-grained mosaic of human settlements and small-holder cultivation plots (Pellikka et al., 2009). Although geologically part of the EAM, the Taita Hills represent a centre of endemism on its own, counting no less than six single-block vertebrate endemics (Burgess et al., $2007 b$ ). For these species, local developments may directly affect their global survival, and given the small total area of indigenous forest remaining, for at least two endemic bird species (A. fuscigularis and T. helleri), the situation is judged critical (IUCN, 2011).

\section{Study species}

We chose to work with two relatively common insectivorous species that are representative of the understory forest bird community of the EAM (Newmark, 1991) but which have been shown to differ in their dependency on intact cloud forest habitat. Within the Taita Hills, P. cabanisi $(30.3 \mathrm{~g})$ only occurs in the indigenous forest fragments (Callens et al., 2011). It forages in pairs or small family groups, predominantly in the understory up to the sub-canopy of the forest (Keith, Urban \& Fry, 1992). P. stellata (19.0 g), on the other hand, inhabits both pristine and disturbed forests (Githiru, Lens \& Bennun, 2007), and has even been found breeding in degraded forest remnants as small as 0.2 ha (T. Spanhove, unpubl. data). It forages at all levels in the forest, most frequently in the undergrowth and in ant trails (Keith et al., 1992). In concordance with this difference in forest dependency, $P$. stellata shows lower genetic population differentiation between three forest fragments in the Taita Hills, suggesting higher matrix permeability (Callens et al., 2011).

\section{Translocation experiments}

Translocation experiments were conducted during February-April 2009, July-August 2009 and FebruaryApril 2010. To minimize disturbance, all experiments were carried out in-between breeding seasons of both species. Birds were captured in four indigenous forest fragments (Ngangao, Chawia, Fururu and Ndiwenyi; Fig. 1) by using standard mist-netting procedures. Upon capture, birds were ringed, aged, measured and weighed, and fitted with either a 


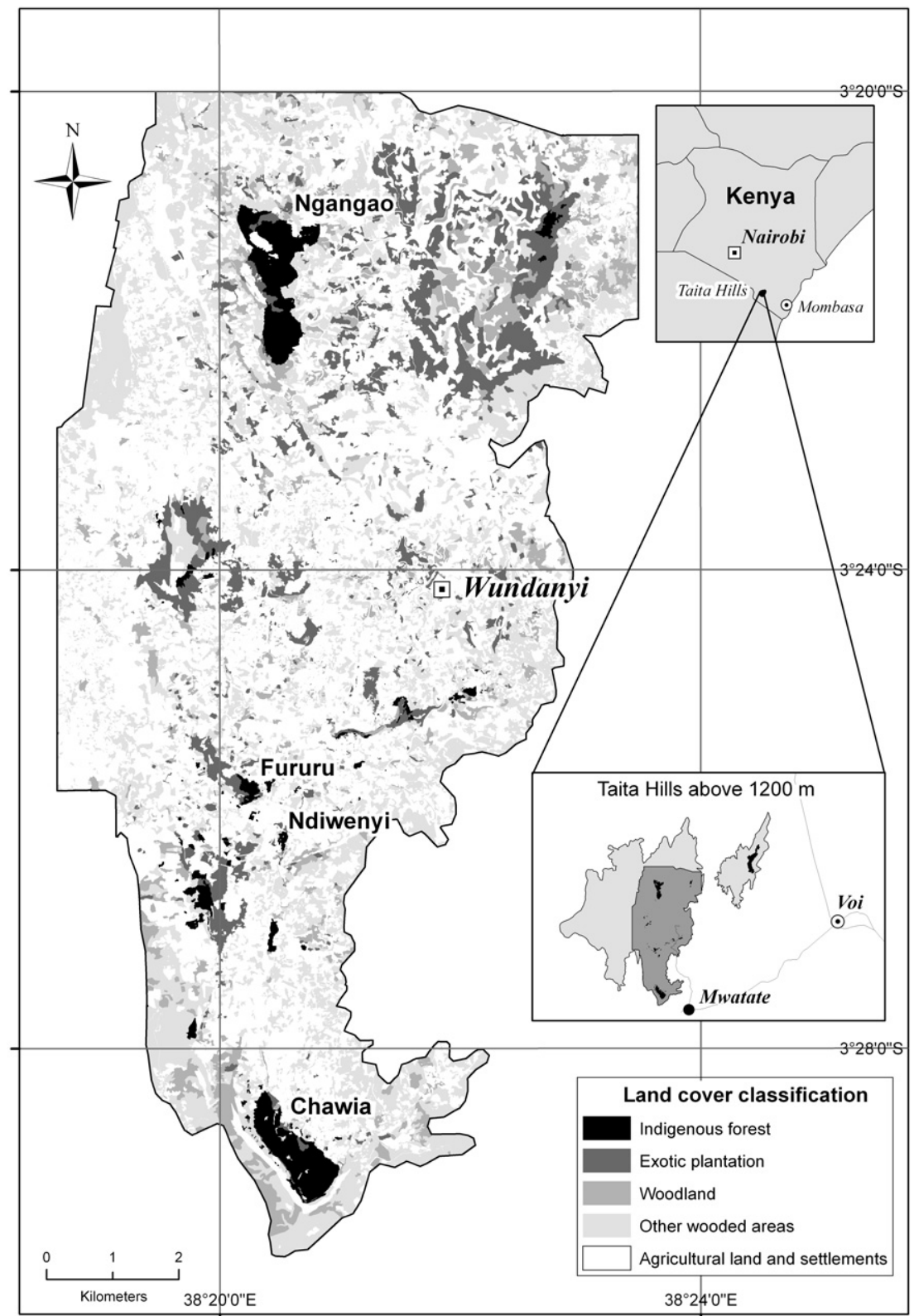

Figure 1 Detail of the land cover map of the Taita Hills massif above $1200 \mathrm{~m}$. Translocation experiments were conducted in the matrix around the indigenous forest fragments Ngangao, Chawia, Fururu and Ndiwenyi.
0.65 or $1.10 \mathrm{~g}$ transmitter (Biotrack Ltd, Dorset, UK). Males and females of neither species can be distinguished based on their plumage; therefore, sex could not reliably be determined. If more than one individual was captured, we selected the individual that appeared to be in the best overall condition, both physical (i.e. weight) and behavioural (alertness). We only used adult birds to exclude possible age effects on movement behaviour. Transmitters were attached on the skin of the back using Lashfix (Eylure), a nonirritating glue that stays flexible after drying. Attachment was designed to last at least 1 full day (duration of a translocation experiment), but thereafter remain on the bird for a minimal amount of time (mean attachment time was 4.3 days \pm 2.9 ), thus minimizing impediment for the birds.
Birds were released in the matrix within approximately 1 hour from the moment of capture between 7 and $10 \mathrm{AM}$ from pre-defined locations. Because we assumed that released birds would show homing behaviour, release sites were selected such that straight lines between location of capture and release site intersected different parts of the matrix and as many land cover classes as possible. In addition, the three study sites (Fig. 1) were chosen such that a representative range of matrix configurations (relative proportions of land cover classes) was covered. Each combination of location of capture and release site was used once for a species. The choice of locations for the release sites was constrained by the extreme topography of the area, but distances relative to the fragment of origin were limited to a range from $400 \mathrm{~m}$ to 

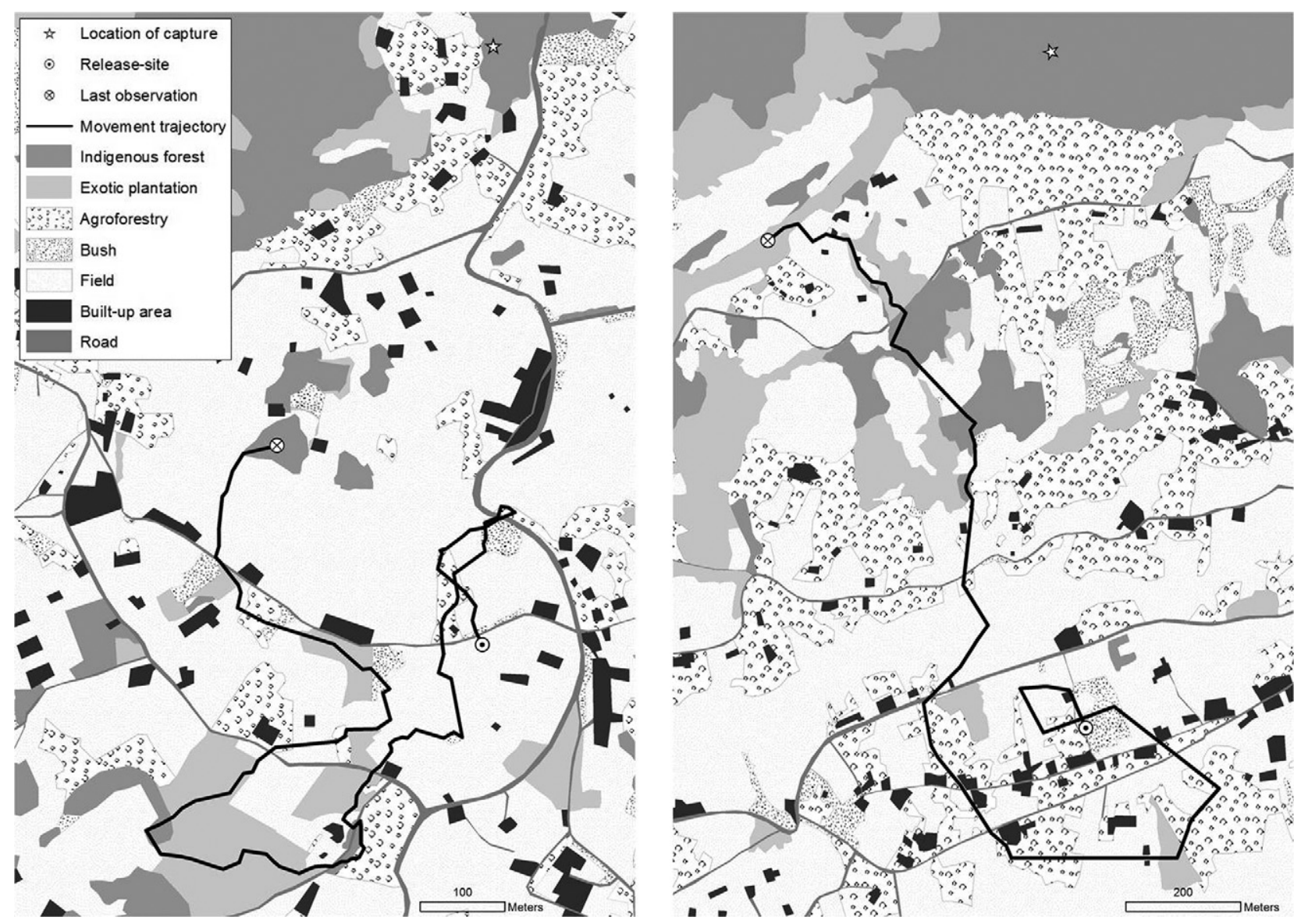

Figure 2 Example trajectories of birds recorded during the translocation experiments overlaid on the land cover model (left Pogonocichla stellata in a landscape with high patch density and right Phyllastrephus cabanisi in a landscape with low patch density - see text for further explanation).

$1000 \mathrm{~m}$. Upon release in a bush or a small patch of woody vegetation, birds were followed by two experienced observers (J. A. and either D. Gitau or N. Mkombola) using continuous radio-tracking. Considerable efforts were made to maintain visual contact with individuals and confirm landing sites after each flight. Locations were recorded by taking global positioning system readings using a GPSMAP 60CSx (Garmin, Olathe, KS, USA). Birds were followed for the rest of the day or until they returned to their home fragment (see Fig. 2 for two example trajectories). A total of 37 individuals of $P$. cabanisi and 34 individuals of $P$. stellata were translocated. Five ( $P$. cabanisi) and two ( $P$. stellata) trajectories were constrained by early drop-off of the transmitters, while four (P. cabanisi) and eight (P. stellata) trajectories were insufficiently documented, and therefore discarded from further analysis.

\section{Land cover information}

Land cover information was derived from digital airborne true-colour images acquired on January 26, 2004 using Nikon D1X camera (Nikon, Tokyo, Japan). Orthorectified image mosaics were generated to a spatial resolution of
$0.5 \mathrm{~m}$ using EnsoMOSAIC software (MosaicMill, Vantaa, Finland), and the mosaics were interpreted visually in ArcGIS (ESRI, Redlands, CA, USA) (Pellikka et al., 2009). For this study, the number of land cover classes of the land cover model was reduced to seven according to their structural characteristics in order to increase the number of individuals of each species that encountered a given land cover class, and thus the accuracy of estimates of the use of the land cover class (Table 1). As the data originate from 2009, the land cover model was checked for changes in the land cover on site as well as by using recent SPOT satellite images published on Google Earth (2010). We first analyzed land cover selection at the landscape scale by comparing land cover attributes of used locations with those of 1000 randomly generated locations that represented available land cover not used by an individual. The available matrix land cover (excluding the main indigenous forest fragments) was sampled within an ellipse with foci on the release and capture location (cf. Gillies \& St. Clair, 2010) and with an eccentricity of 0.68 (Table 2). This shape captured $95 \%$ of all the point locations of individuals, and thus approximated the area used by homing birds. Only visually confirmed locations were selected for the analyses, which resulted in 
Table 1 Description of the original land cover classes used in the land cover model of the Taita Hills (modified from Pellikka et al., 2009)

\begin{tabular}{lll}
\hline Original class & Description & Land cover class in this study \\
\hline Indigenous forest & Natural broad-leaved vegetation of trees over $14 \mathrm{~m}$ high and over $65 \%$ canopy & Indigenous forest \\
Woodland & Natural broad-leaved vegetation of trees and woody shrubs with a height $>3 \mathrm{~m}$ & Indigenous forest \\
Eucalyptus forest & Semi-natural broad-leaved vegetation of trees over $14 \mathrm{~m}$ high and over $65 \%$ canopy & Exotic plantation \\
Pine forest & Semi-natural needle-leaved vegetation of trees over $14 \mathrm{~m}$ high and over $65 \%$ canopy & Exotic plantation \\
Cypress forest & Semi-natural needle-leaved vegetation of trees over $14 \mathrm{~m}$ high and over $65 \%$ canopy & Exotic plantation \\
Grevillea forest & Semi-natural broad-leaved vegetation of trees over $14 \mathrm{~m}$ high and over $65 \%$ canopy & Exotic plantation \\
Agroforestry & Multi-functional vegetated small-sized fields of herbaceous crops and woody shrubs or trees & Agroforestry \\
Bush & Natural or exotic broad-leaved vegetation of woody shrubs 3-5 m high & Bush \\
Wetland & Natural aquatic or regularly flooded herbaceous vegetation $0.5-3 \mathrm{~m}$ high & Bush \\
Rock & Bare rocks with scattered shrub, grass, lichen or moss cover & Field \\
Water & Natural or semi-natural permanent or temporal water bodies & Field \\
Agricultural land & Vegetated or un-vegetated small-sized fields of rain fed herbaceous crops & Field \\
Barren land & Natural or man-made barren soil without vegetation cover & Field \\
Road & Relatively narrow (up to $6 \mathrm{~m}$ ) dirt roads with low-intensity motorized traffic & Road \\
Built-up & Un-vegetated or sparsely vegetated areas, typically buildings and homesteads & Built-up \\
\hline
\end{tabular}

a Land cover class not described in Pellikka et al. (2009).

Table 2 Land cover amounts in the matrix, including means and standard deviations, measured in the ellipses $(n=52)$

\begin{tabular}{lc}
\hline Indigenous forest & $8.21 \pm 3.96$ \\
Exotic plantation & $6.80 \pm 4.29$ \\
Bush & $8.52 \pm 3.24$ \\
Field & $58.38 \pm 8.90$ \\
Agroforestry & $18.09 \pm 7.86$ \\
Built-up & $1.11 \pm 0.34$ \\
Road & $65.70 \pm 15.45$ \\
\hline
\end{tabular}

All values are given as percentages except for built-up (number of houses $\left.\mathrm{ha}^{-1}\right)$ and road $\left(\mathrm{m} \mathrm{ha}^{-1}\right)$.

1123 locations for $P$. cabanisi and 1048 locations for $P$. stellata. To investigate whether structural landscape configuration affected land cover selection, we calculated a fragmentation index (patch density) for each ellipse using the Patch Grid extension (version 4.2) for ArcGIS (Rempel, Carr \& Kaukinen, 2008). For this purpose, we created a binary landscape of vegetated land cover classes (lumping non-field land cover classes) and field. We used the function pamk in the fpc package (Hennig, 2010) to perform a cluster analysis on the variable patch density, which resulted in the delineation of two clusters of high $(n=30)$ and low patch density $(n=22)$ ellipses.

In the second analysis, we focused on land cover selection during movement by contrasting land cover attributes of each observed step with land cover attributes of 20 randomly generated steps from the same location. We only used those steps for which relatively good route information was available and of at least $5 \mathrm{~m}$ length, resulting in 1075 observed steps for P. cabanisi and 1025 for P. stellata. To ensure that alternative steps were realistic, their step lengths and turning angles were randomly drawn from specified distributions calculated from the observed steps (pooled for each species). Random steps were created using the tool movement.ssfsamples, which is available in the program Geospatial Modeling Environment (Beyer, 2011).
In a final analysis, we investigated the response to ecotones by analyzing turning angles. We selected all steps starting within $20 \mathrm{~m}$ of an ecotone that were preceded by a step towards the ecotone ( $\leq 45^{\circ}$ angle). We compared the angle between the current and the previous step between ecotones of low contrast (between vegetated land cover types) and high contrast (between vegetated land cover classes and field).

\section{Statistical analyses}

All statistical analyses were carried out using $\mathrm{R}$ version 2.13.0 (R Development Core Team, 2011). Land cover selection at the landscape scale was analyzed using selection ratios (Manly et al., 2002). For land cover type $h$, the selection ratio corresponds to the ratio between the proportion of land cover type $h$ used and the proportion of land cover type $h$ available. Selection ratios were $\ln$-transformed, adding 0.1 to allow calculation of $\ln$-selection ratios for non-used land cover classes. Generalized linear mixed models were used to analyze variation in $\ln$-selection ratios for the five land cover classes with individual and the individual by land cover type interaction as random effects added to the models to control for repeated observations (across land cover types) per individual. To investigate differences in land cover selection between species and between landscape configuration types, a two-way interaction between species and land cover type and between configuration type and land cover type was included in the models. Models were fitted with the lmer function in the lme4 package (Bates, Maechler \& Bolker, 2011).

Effects of land cover on step selection were analyzed by matched case-control logistic regression (sensu Gillies et al., 2011). Landscape characteristics of each observed step were compared with characteristics of 20 alternative steps sharing the same starting point. As we were interested in the relative contribution of the different land cover classes on the route decisions of the birds, the main explanatory variables were the proportions of indigenous forest, exotic plantation, 


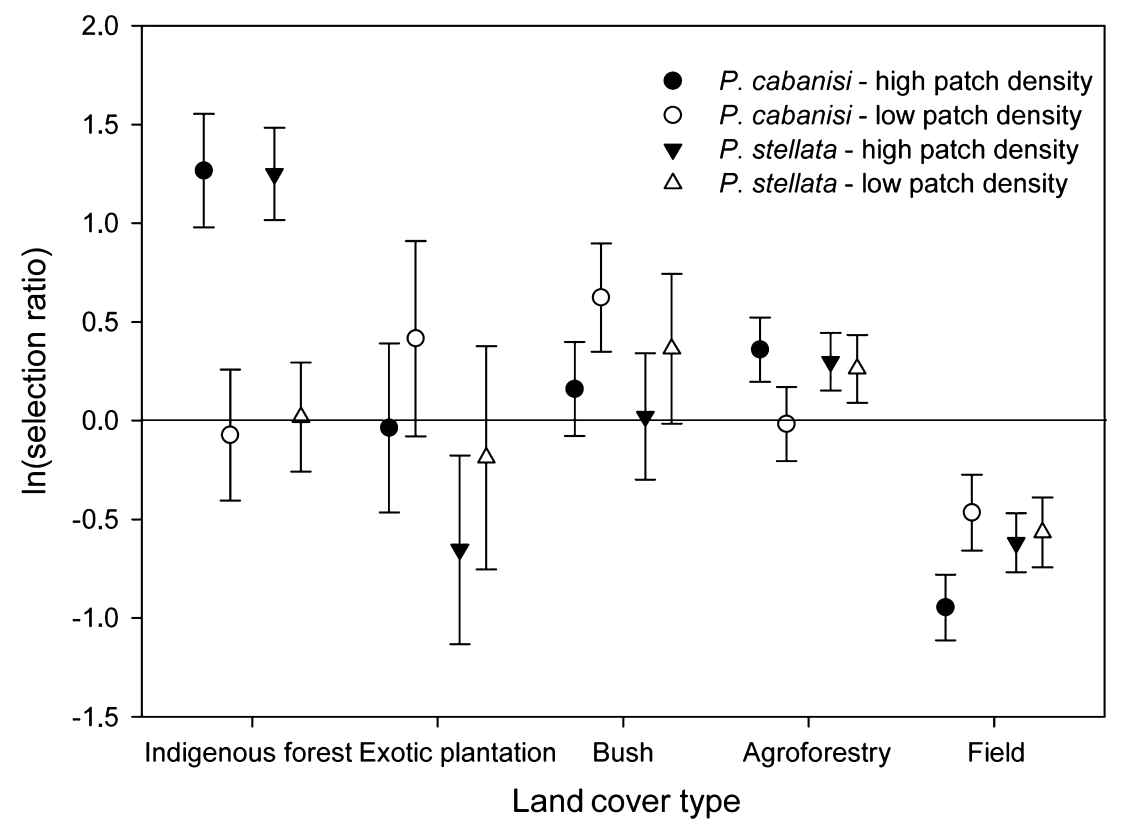

Figure 3 Ln-transformed selection ratios \pm SE of the five land cover classes by translocated individuals of the two study species in the two landscape configuration types. $\mathrm{SE}$, standard error. bush, agroforestry and field within each step. As additional variables, we included the cumulative width $(\mathrm{m})$ of roads in the step and a binary variable describing whether the step intersected a built-up area. Because the model did not converge when all five of the above-mentioned proportional variables were introduced together, we compared their explanatory power one by one with an intercept model and retained those variables that yielded the lowest Aikake Information Criterion relative to the intercept model. To control for the effect of homing behaviour on step selection, we included the deviation (degrees) of each step from the optimal homing direction as a covariate in the model. A mixed-effect logistic regression was fitted with the function lmer with individual and case as random effects added to the models to control for repeated observations per individual, and to group each observed step with the corresponding 20 alternative steps. The relative importance of the predictor variables on step selection was assessed for each species separately by fitting all possible combinations of the selected covariates using the function dredge in the MuMIn package (Bartoń, 2011), and by extracting the model averaged coefficients and relative importance (calculated as a sum of the Akaike weights over all of the models in which that particular covariate is included) for each covariate using the function model.avg (MuMIn). Model averaging was performed on a subset of models ( $n=12$ for both species) with a cumulative weight $>95 \%$ of the total weight of all models.

Turning angles at ecotones were analyzed using linear mixed effects models with individual and group (i.e. lowcontrast ecotone and high-contrast ecotone) added as a crossed random effect to take into account that an individual may be represented in the dataset by more than one observation and in more than one group. A likelihood ratio test (using maximum likelihood) was used to test if turning angles differed between groups.
Table 3 Candidate models to investigate land cover selection for both species at the landscape scale with configuration type (high vs. low patch density) in interaction with land cover type and with individual identity nested in land cover type as a random effect

\begin{tabular}{lll}
\hline Model & AICc $(\mathrm{K})$ & $\Delta \mathrm{AICC}\left(W_{\mathrm{i}}\right)$ \\
\hline Phyllastrephus cabanisi & & \\
$\quad$ Land cover $\times$ configuration & $447.56(26)$ & $0.00(0.71)$ \\
$\quad$ Land cover & $449.30(21)$ & $1.74(0.29)$ \\
$\quad$ Intercept & $464.50(17)$ & $16.94(0.00)$ \\
$\begin{array}{l}\text { Pogonocichla stellata } \\
\text { Land cover }\end{array}$ & $369.44(21)$ & $0.00(0.94)$ \\
Land cover $\times$ configuration & $375.06(26)$ & $5.62(0.06)$ \\
Intercept & $388.14(17)$ & $18.70(0.00)$ \\
\hline
\end{tabular}

AIC, Aikake Information Criterion.

\section{Results}

\section{Land cover selection at the landscape scale}

In general, variation in selection ratios for both species was best explained by models containing land cover type (Table 3), which indicates that the composition of the matrix was an important factor in driving movement behaviour of our focal species. In addition, we found evidence for an effect of landscape configuration on land cover selection for $P$. cabanisi (Table 3 ). In P. stellata, the effect of configuration type had little model support (Table 3), although results in Fig. 3 show that use of indigenous forest differed among configuration types to the same degree in both species. Both species had a clear preference for indigenous forest in the high patch density landscapes, but not in the landscapes with lower patch density where this land cover type was used proportionally to availability (Fig. 3). Use of 
Table 4 Model averaged coefficients, standard errors and relative importance (see Methods for explanation) for the step selection of both species. Coefficients describe how each variable contributes to the likelihood of the observed step being chosen compared with random steps

\begin{tabular}{|c|c|c|c|c|}
\hline Species & Variable & Coefficient & SE & $\operatorname{Imp}$ \\
\hline \multirow[t]{8}{*}{ Phyllastrephus cabanisi } & (Intercept) & -2.348 & 0.083 & \\
\hline & Deviance from homing direction (degrees) & -0.005 & 0.001 & 1.00 \\
\hline & Proportion indigenous forest & 0.179 & 0.101 & 0.68 \\
\hline & Proportion agroforestry & 0.060 & 0.116 & 0.29 \\
\hline & Proportion exotic plantation & -0.061 & 0.128 & 0.28 \\
\hline & Proportion field & -0.586 & 0.094 & 1.00 \\
\hline & Cumulative distance of roads $(\mathrm{m})$ & 0.006 & 0.016 & 0.23 \\
\hline & Presence of built-up (yes/no) & -0.988 & 0.195 & 1.00 \\
\hline \multirow[t]{8}{*}{ Pogonocichla stellata } & (Intercept) & -2.351 & 0.065 & \\
\hline & Deviance from homing direction (degrees) & -0.004 & 0.001 & 1.00 \\
\hline & Proportion indigenous forest & 0.056 & 0.106 & 0.27 \\
\hline & Proportion agroforestry & 0.056 & 0.095 & 0.28 \\
\hline & Proportion exotic plantation & -0.054 & 0.105 & 0.25 \\
\hline & Proportion field & -0.669 & 0.086 & 1.00 \\
\hline & Cumulative width of roads $(\mathrm{m})$ & -0.009 & 0.018 & 0.27 \\
\hline & Presence of built-up (yes/no) & -0.784 & 0.202 & 1.00 \\
\hline
\end{tabular}

$\mathrm{SE}$, standard error.

exotic plantations did not differ from availability except for $P$. stellata, which avoided plantations in low patch density landscapes (Fig. 3). Both species tended to prefer rather than to avoid bush, but this was significant only in $P$. cabanisi in high patch density landscapes. Agroforestry was used more often than expected (although to a lesser extent than indigenous forest) by $P$. cabanisi in all landscapes, but in the case of $P$. stellata, this was only true in low patch density landscapes. Finally, both species clearly avoided fields, with an especially strong avoidance in $P$. cabanisi in the high patch density landscapes.

\section{Step selection and movement behaviour at ecotones}

Model averaged coefficients show that both species were more likely to select steps that were oriented towards the location of capture, reflecting the homing behaviour. In both species, observed steps were less likely to cross fields and built-up areas than random steps (Table 4). In addition, observed movements in $P$. cabanisi contained higher proportions of indigenous forest and woodland than random steps, while this was not true for $P$. stellata. The remaining predictor variables had relatively little importance $(0.3$ or lower), indicating that step choice was not consistently related to these explanatory variables.

Turning angles of birds at contrasting ecotones were significantly higher compared with those at ecotones between vegetated land cover classes (Fig. 4; P. cabanisi, $X^{2}=9.10$, d.f. $=1, \quad P=0.0026 ; \quad P$. stellata $, \quad X^{2}=5.46, \quad$ d.f. $=1$, $P=0.020)$. The effect was similar for both species $\left(X^{2}=0.054\right.$, d.f. $\left.=4, P=0.82\right)$. The maximum gap-crossing distances (field crossed in a single flight) recorded were $102 \mathrm{~m}$ (mean $25.12 \pm 19.18$ ) for P. cabanisi and $112 \mathrm{~m}$ (mean $24.09 \pm 18.41$ ) for $P$. stellata (no significant difference between species).

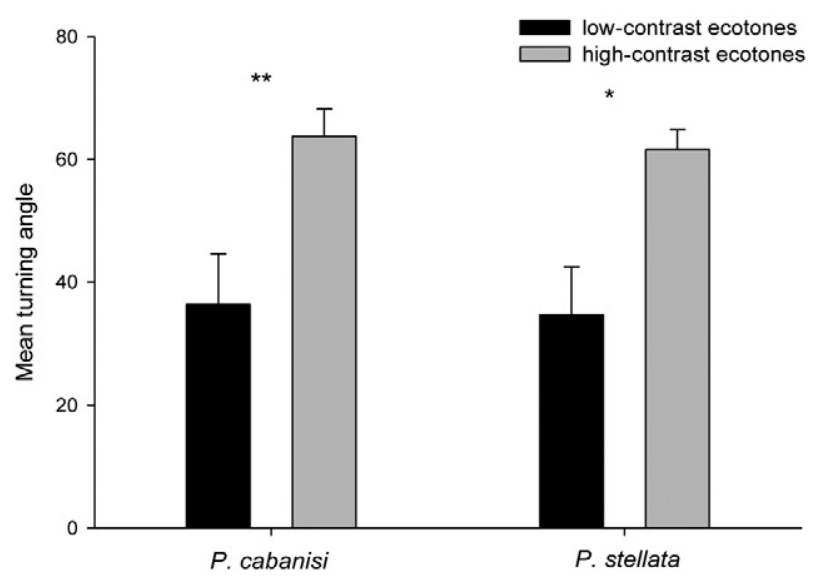

Figure 4 Mean $( \pm S E$ ) turning angles of steps when birds approach contrasting ecotones (vegetated land cover classes vs. field) and ecotones of lower contrast (between vegetated land cover classes). ${ }^{*} P<0.05 ;{ }^{*} P<0.01$. SE, standard error.

\section{Discussion}

The translocation experiments indicated that even a relatively fine-grained and heterogeneous matrix represented sufficient contrasts for our focal species to result in nonrandom land cover selection, both at the landscape scale and at the scale of movement steps. The analysis on land cover attributes of point locations showed that birds used indigenous forest, bush and agroforestry more than expected, and avoided open land cover types. This relative preference for vegetated land cover types is in concordance with the results of other studies (Hadley \& Betts, 2009; Gillies \& St. Clair, 2010), and may reflect the tendency of forest birds to use land cover structure as a cue to assess its suitability for movement. However, our study indicates 
that this pattern was influenced by matrix configuration; selection of indigenous forest (both species) and agroforestry ( $P$. cabanisi only), and avoidance of open land cover types ( $P$. cabanisi only) was stronger in landscapes with a relatively high patch density, representing a more highly fragmented matrix. This may indicate that in landscapes where the amount of contrasting edge (ecotones between vegetated land cover types and open land cover types) is high, birds tend to be more reluctant to leave preferred land cover types compared with less contrasting landscapes. This is in agreement with the work of Castellon \& Sieving (2006), who showed for a forest understory insectivore that reluctance to leave a habitat patch increased with increasing contrast between the patch and the surrounding matrix.

The analysis on step selection showed that birds were more likely to select steps that took them closer to the location of capture, contained lower proportions of field and crossed fewer built-up areas, and, for P. cabanisi, contained higher proportions of indigenous forest. This supports the result of the first analysis. Strong avoidance of field implies that in patchy landscapes, birds will more often be deflected from their route and potentially become 'trapped' in relatively suitable patches from where they are reluctant to depart again. This is further exemplified by the result on the behavioural response of individuals at ecotones, showing a stronger tendency to be deflected at contrasting edges. This indicates that both composition and configuration of the matrix will have strong effects on bird movements at the landscape scale and clearly is an important factor to take into account when quantifying landscape connectivity for these two species. We also found some effects of human activities on bird movements. Birds avoided flying over houses, although our detailed observations indicate that they often approached houses closely and even foraged in homesteads. This shows that built-up areas, in this setting, are not strongly perceived to be hostile land cover and that their negative impact on landscape connectivity is not greater than their actual size in the landscape. The small effects of roads on step choice is in concordance with our expectations given the fact that the maximum width of roads in the Taita Hills lies well below described thresholds in road-crossing probabilities of forest-dependent birds (Awade \& Metzger, 2008; Tremblay \& St Clair, 2009).

The fact that translocated individuals of our focal species clearly had the propensity to return to their fragment of origin may have affected results for the step selection, even though we included homing direction as a covariate in the analysis. Spontaneous dispersing individuals have no predefined goals, and hence may be less motivated to cross potentially hazardous habitats or to use suboptimal habitats. This would imply that in similar landscapes, movement paths of dispersers should be relatively more tortuous. Theory, however, has pointed out that individuals dispersing in fragmented landscapes should follow rather straight paths in order to maximize survival and to locate new habitat patches most effectively (Zollner \& Lima, 1999; Bartoń et al., 2012). In support of this,
Delgado et al. (2009) showed that individual eagle owls Bubo bubo moving in unfamiliar landscapes had straighter paths with longer move steps compared with movements of breeders. This suggests that dispersers make different movement decisions in relation to the landscape, perhaps in a relatively similar way to translocated individuals. In any case, we feel that the reported difference in preference between matrix covers is likely to be representative of the way dispersal of tropical forest birds is affected by habitat fragmentation.

The differences between the two species in relative land cover selection were relatively small but in line with expectations. The stronger response of the forest specialist $P$. cabanisi to more fragmented landscapes and its preference to select steps through indigenous forest suggests that for this species, functional connectivity will be more impeded by the matrix compared with the forest generalist P. stellata. This is also supported by the proportion of individuals that returned to their fragment of origin within the course of the 1-day trial, which was higher - although not significantly - in P. stellata (11 out of $24,46 \%$ ) than in P. cabanisi ( 9 out of $28,32 \%$ ). However, we want to stress that our study was not designed to test landscape effects on homing success. This would have required multiple day trials [e.g. mean return time for forest birds in a similar translocation experiment was 26.2 and 33.7 daylight hours (Gillies \& St. Clair, 2008)] as well as a more standardized choice of release locations for the two species. In any case, these results indicate that species-specific differences in landscape connectivity may contribute to the observed differences in patch occupancy and genetic differentiation among fragments for these two species (Callens et al., 2011), and support the view that landscape connectivity cannot be generalized for forest bird communities in fragmented landscapes (Lees \& Peres, 2008).

\section{Implications for conservation}

Because patch isolation is one of the most important determinants of species extinction in fragmented landscapes (Lees \& Peres, 2006), restoration of matrix habitat to increase landscape connectivity can be an effective instrument for the conservation of species (Taylor, Fahrig \& With, 2006; Prugh et al., 2008). Specifically for the Taita Hills, a recent molecular study has shown that patch isolation was negatively related to genetic connectivity for several forest bird species (Callens et al., 2011). Given the fact that in the Taita Hills the remaining indigenous forest fragments are small, survival of most forest bird species will therefore strongly depend on sufficient connectivity between patches (Lens et al., 2002). However, our results suggest that the matrix constrains connectivity between fragments. Moreover, the observed negative relationship between degree of forest dependency and matrix permeability, which is in line with the results of a recent similar study (Gillies \& St. Clair, 2008), implies that for species that are even more dependent on intact forest habitat than 
P. cabanisi (i.e. forest interior species like T. helleri), current permeability of the matrix may be even lower (Newmark, Mkongewa \& Sobek, 2010).

Our study was performed in a fine-grained, heterogeneous matrix, exemplary for other small-scale subsistence farming areas, and one could hypothesize that the high density of vegetated land cover types results in a relatively permeable matrix for forest-dependent birds. However, this seems to be true only for the forest generalist $P$. stellata, for which all vegetated land cover classes were equally permeable. The forest specialist's clear preference to move through indigenous forest implies that for this species, permeable land cover is much more fragmented than for P. stellata, and it consequently has to cross sub-optimal land cover types more frequently in order to traverse the matrix. This strongly suggests that inter-patch movement rates of (understory) forest birds, which exhibit similar or even stronger associations with indigenous forest compared to $P$. cabanisi, are highly dependent on the presence of corridors of indigenous forest. This conclusion is in concordance with other studies that have shown that translocated forest birds returned to their territories faster and with greater success in forested landscapes relative to landscapes with low forest cover (Belisle, Desrochers \& Fortin, 2001; Gobeil \& Villard, 2002; Kennedy \& Marra, 2010), and that they used forested corridors (Hadley \& Betts, 2009) or linear landscape features (e.g. riparian forest strips [Gillies \& St. Clair, 2008]) rather than to cross non-forested land covers while homing.

However, indigenous forest is scarce and patchy distributed across the Taita Hills matrix. And as projected intensification of agriculture in the Taita Hills (Maeda et al., 2010) most likely will further decrease permeability of the matrix for forest birds, habitat restoration is urgently needed to increase indigenous forest cover in the matrix (preferably of linear configuration), which in turn will increase matrix connectivity. This study represents the first step to address this issue. The results on land cover use will be used subsequently to model connectivity and population viability for forest birds in the Taita Hills, with the ultimate goal of identifying priority areas for habitat restoration in the matrix (Githiru et al., 2011).

\section{Acknowledgements}

We are obliged to the Kenyan government for authorizing this research program (NCST Ref. no. 5/002/R/274/4). JA thanks D. Gitau (ornithology section of the National Museums of Kenya) and N. Mkombola for their assistance in the field, T. Callens and M. Chovu for logistic support, M. Githiru for administrative support, Taita Research Station of the University of Helsinki (Wundanyi) for their hospitality and M.P. Dorenbosch for her invaluable personal support. This study was supported by a VLIRVLADOC scholarship awarded to JA, an Academy of Finland grant to PP and FWO grant G.0055.08 to EM and LL.

\section{References}

Awade, M. \& Metzger, J.P. (2008). Using gap-crossing capacity to evaluate functional connectivity of two atlantic rainforest birds and their response to fragmentation. Austral Ecol. 33, 863-871.

Bartoń, K. (2011). MuMIn: multi-model inference. R package version 1.6.0. Available at http://CRAN.Rproject.org/package=MuMIn.

Bartoń, K.A., Hovestadt, T., Phillips, B.L. \& Travis, J.M.J. (2012). Risky movement increases the rate of range expansion. Proc. Biol. Sci. 279, 1194-1202.

Bates, D., Maechler, M. \& Bolker, B. (2011). lme4: linear mixed-effects models using S4 classes. R package version 0.999375-39. Available at http://CRAN.R-project.org/ package $=1 m e 4$.

Beentje, H.J. (1988). An ecological and floristic study of the forests of the Taita Hills, Kenya. Utafiti 1, 23-66.

Belisle, M. (2005). Measuring landscape connectivity: the challenge of behavioral landscape ecology. Ecology 86, 1988-1995.

Belisle, M., Desrochers, A. \& Fortin, M.J. (2001). Influence of forest cover on the movements of forest birds: a homing experiment. Ecology 82, 1893-1904.

Beyer, H.L. (2011). Geospatial Modelling Environment (version 0.5.4 Beta). (software). Available at http:// www.spatialecology.com/gme.

Burgess, N.D., Balmford, A., Cordeiro, N.J., Fjeldsa, J., Kuper, W., Rahbek, C., Sanderson, E.W., Scharlemann, J.P.W., Sommer, J.H. \& Williams, P.H. (2007a). Correlations among species distributions, human density and human infrastructure across the high biodiversity tropical mountains of Africa. Biol. Conserv. 134, 164-177.

Burgess, N.D., Butynski, T.M., Cordeiro, N.J., Doggart, N.H., Fjeldsa, J., Howell, K.M., Kilahama, F.B., Loader, S.P., Lovett, J.C., Mbilinyi, B., Menegon, M., Moyer, D.C., Nashanda, E., Perkin, A., Rovero, F., Stanley, W.T. \& Stuart, S.N. (2007b). The biological importance of the Eastern Arc Mountains of Tanzania and Kenya. Biol. Conserv. 134, 209-231.

Callens, T., Galbusera, P., Matthysen, E., Durand, E.Y., Githiru, M., Huyghe, J.R. \& Lens, L. (2011). Genetic signature of population fragmentation varies with mobility in seven bird species of a fragmented Kenyan cloud forest. Mol. Ecol. 20, 1829-1844.

Castellon, T.D. \& Sieving, K.E. (2006). An experimental test of matrix permeability and corridor use by an endemic understory bird. Conserv. Biol. 20, 135-145.

Delgado, M.D., Penteriani, V., Nams, V.O. \& Campioni, L. (2009). Changes of movement patterns from early dispersal to settlement. Behav. Ecol. Sociobiol. 64, 35-43.

Edwards, D.P., Hodgson, J.A., Hamer, K.C., Mitchell, S.L., Ahmad, A.H., Cornell, S.J. \& Wilcove, D.S. (2010). Wildlife-friendly oil palm plantations fail to protect biodiversity effectively. Conserv. Lett. 3, 236-242. 
Estrada, A., Coates-Estrada, R. \& Meritt, D.A. (1997). Anthropogenic landscape changes and avian diversity at Los Tuxtlas, Mexico. Biodivers. Conserv. 6, 19-43.

Gibson, L., Lee, T.M., Koh, L.P., Brook, B.W., Gardner, T.A., Barlow, J., Peres, C.A., Bradshaw, C.J.A., Laurance, W.F., Lovejoy, T.E. \& Sodhi, N.S. (2011). Primary forests are irreplaceable for sustaining tropical biodiversity. Nature 478, 378-381.

Gillies, C.S., Beyer, H.L. \& St. Clair, C.C. (2011). Finescale movement decisions of tropical forest birds in a fragmented landscape. Ecol. Appl. 21, 944-954.

Gillies, C.S. \& St. Clair, C.C. (2008). Riparian corridors enhance movement of a forest specialist bird in fragmented tropical forest. Proc. Natl Acad. Sci. USA 105, 19774-19779.

Gillies, C.S. \& St. Clair, C.C. (2010). Functional responses in habitat selection by tropical birds moving through fragmented forest. J. Appl. Ecol. 47, 182-190.

Githiru, M., Lens, L., Adriaensen, F., Mwang'ombe, J. \& Matthysen, E. (2011). Using science to guide conservation: from landscape modelling to increased connectivity in the Taita Hills, se Kenya. J. Nat. Conserv. 19, 263268.

Githiru, M., Lens, L. \& Bennun, L. (2007). Ranging behaviour and habitat use by an afrotropical songbird in a fragmented landscape. Afr. J. Ecol. 45, 581-589.

Gobeil, J.F. \& Villard, M.A. (2002). Permeability of three boreal forest landscape types to bird movements as determined from experimental translocations. Oikos 98, 447458.

Google. (2010). Google Earth (Version 6). Available at http://www.google.com/earth/download/ge/agree.html (accessed 10 March 2011).

Hadley, A.S. \& Betts, M.G. (2009). Tropical deforestation alters hummingbird movement patterns. Biol. Lett. 5, 207-210.

Hall, J., Burgess, N.D., Lovett, J., Mbilinyi, B. \& Gereau, R.E. (2009). Conservation implications of deforestation across an elevational gradient in the Eastern Arc Mountains, Tanzania. Biol. Conserv. 142, 2510-2521.

Hennig, C. (2010). fpc: flexible procedures for clustering. R package version 2.0-3. Available at http://CRAN.Rproject.org/package $=$ fpc.

IUCN. (2011). IUCN Red List of Threatened Species. Version 2011.2. Available at http://www.iucnredlist.org (accessed 2 January 2012).

Keith, S., Urban, E.K. \& Fry, C.H. (Eds). (1992). The birds of Africa. Vol. IV, London: Academic Press.

Kennedy, C.M. \& Marra, P.P. (2010). Matrix mediates avian movements in tropical forested landscapes: inference from experimental translocations. Biol. Conserv. 143, 2136-2145.

Lees, A.C. \& Peres, C.A. (2006). Rapid avifaunal collapse along the Amazonian deforestation frontier. Biol. Conserv. 133, 198-211.
Lees, A.C. \& Peres, C.A. (2008). Avian life-history determinants of local extinction risk in a hyper-fragmented neotropical forest landscape. Anim. Conserv. 11, 128-137.

Lens, L., Van Dongen, S., Norris, K., Githiru, M. \& Matthysen, E. (2002). Avian persistence in fragmented rainforest. Science 298, 1236-1238.

Lens, L., Van Dongen, S., Wilder, C.M., Brooks, T.M. \& Matthysen, E. (1999). Fluctuating asymmetry increases with habitat disturbance in seven bird species of a fragmented Afrotropical forest. Proc. R. Soc. Lond. B Biol. Sci. 266, 1241-1246.

Levey, D.J., Bolker, B.M., Tewksbury, J.J., Sargent, S. \& Haddad, N.M. (2005). Effects of landscape corridors on seed dispersal by birds. Science 309, 146-148.

Maeda, E.E., Clark, B.J.F., Pellikka, P. \& Siljander, M. (2010). Modelling agricultural expansion in Kenya's Eastern Arc Mountains biodiversity hotspot. Agric. Syst. 103, 609-620.

Manly, B.F.J., McDonald, L.L., Thomas, D.L., McDonald, T.L. \& Erickson, W.P. (2002). Resource selection by animals: statistical design and analysis for field studies. Norwell, MA: Kluwer Academic Publishers.

Myers, N., Mittermeier, R.A., Mittermeier, C.G., Da Fonseca, G.A.B. \& Kent, J. (2000). Biodiversity hotspots for conservation priorities. Nature 403, 853-858.

Newmark, W.D. (1991). Tropical forest fragmentation and the local extinction of understory birds in the Eastern Usambara Mountains, Tanzania. Conserv. Biol. 5, 67-78.

Newmark, W.D., Mkongewa, V.J. \& Sobek, A.D. (2010). Ranging behavior and habitat selection of terrestrial insectivorous birds in north-east Tanzania: implications for corridor design in the Eastern Arc Mountains. Anim. Conserv. 13, 474- 482.

Pellikka, P.K.E., Lotjonen, M., Siljander, M. \& Lens, L. (2009). Airborne remote sensing of spatiotemporal change (1955-2004) in indigenous and exotic forest cover in the Taita Hills, Kenya. Int. J. Appl. Earth Obs. Geoinf. 11, 221-232.

Phalan, B., Onial, M., Balmford, A. \& Green, R.E. (2011). Reconciling food production and biodiversity conservation: land sharing and land sparing compared. Science 333, 1289-1291.

Prugh, L.R., Hodges, K.E., Sinclair, A.R.E. \& Brashares, J.S. (2008). Effect of habitat area and isolation on fragmented animal populations. Proc. Natl Acad. Sci. USA 105, 20770-20775.

R Development Core Team. (2011). R: a language and environment for statistical computing. R Foundation for Statistical Computing, Vienna, Austria. ISBN 3-90005107-0. Available at http://www.R-project.org/.

Rempel, R.S., Carr, A.P. \& Kaukinen, D. (2008). Patch Grid extension for ArcMap: version 4.2. Ontario Ministry of Natural Resources. Available at http://flash. lakeheadu.ca/ rrempel/patch. 
Stouffer, P.C. \& Bierregaard, R.O. (1995). Use of amazonian forest fragments by understory insectivorous birds. Ecology 76, 2429-2445.

Taylor, P.D., Fahrig, L., Henein, K. \& Merriam, G. (1993). Connectivity is a vital element of landscape structure. Oikos 68, 571-573.

Taylor, P.D., Fahrig, L. \& With, K.A. (2006). Landscape connectivity: a return to the basics. In Connectivity conservation: 29-43. Crooks, K.R. \& Sanjayan, M. (Eds).

Cambridge: Cambridge University Press.
Tremblay, M.A. \& St Clair, C.C. (2009). Factors affecting the permeability of transportation and riparian corridors to the movements of songbirds in an urban landscape. $J$. Appl. Ecol. 46, 1314-1322.

Zollner, P.A. \& Lima, S.L. (1999). Search strategies for landscape-level interpatch movements. Ecology 80, 10191030 . 